
Winnipeg, Canada

Marcie Snyder, PhD

Department of Geography, University of Toronto Mississauga

Kathi Wilson, $\mathrm{PhD}$

Department of Geography, University of Toronto Mississauga

Jason Whitford, Program Manager

Eagle Urban Transition Centre, Winnipeg, Manitoba, Canada

aboriginal policy studies Vol. 5, no. 1, 2015, pp. 3-27

This article can be found at:

http://ejournals.library.ualberta.ca/index.php/aps/article/view/23259

ISSN: 1923-3299

Article DOI: http://dx.doi.org/10.5663/aps.v5i1.23259

aboriginal policy studies is an online, peer-reviewed and multidisciplinary journal that publishes original, scholarly, and policy-relevant research on issues relevant to Métis, non-status Indians and urban Aboriginal people in Canada. For more information, please contact us at apsjournal@ualberta.ca or visit our website at www.nativestudies.ualberta.ca/research/aboriginal-policy-studies-aps. 


\title{
Examining the Urban Aboriginal Policy Gap: Impacts on Service Delivery for Mobile Aboriginal Peoples in Winnipeg, Canada
}

\author{
Marcie Snyder, PhD \\ Department of Geography, University of Toronto Mississauga \\ Kathi Wilson, $\mathrm{PhD}$ \\ Department of Geography, University of Toronto Mississauga \\ Jason Whitford, Program Manager \\ Eagle Urban Transition Centre, Winnipeg, Manitoba, Canada
}

\begin{abstract}
In recent decades, Aboriginal peoples in Western settler nations have become increasingly urbanized. In many cases, urbanization has been associated with notably high levels of geographic mobility between rural/reserve areas and cities, as well as within cities. Despite the increasing urbanization of Aboriginal peoples in Canada, the policy environment in Canada remains focused on the reserve-based population. Drawing upon thirty-nine in-depth interviews with mobile, urban Aboriginal peoples and urban Aboriginal service providers in Winnipeg, Canada, this article demonstrates that colonial-rooted policy and legislation, along with federal downscaling and privatization of social services, have had an impact on how service providers operate. This has resulted in service gaps between urban and rural/reserve areas, as Aboriginal migrants seek out information and support from housing, employment, education, health and social-related services. This leaves Aboriginal migrants often unprepared for their transition from rural/reserve areas to cities. Intra-city movers also experience difficulty maintaining continuous social and health-service care as they travel across urban neighbourhoods. The research findings suggest a need for urban Aboriginal policies that reflect the right to self-determination and adequate service delivery, as service providers remain constrained by neoliberalism, government funding restrictions, and service delivery models that do not acknowledge urban Aboriginal peoples' mobility experiences.
\end{abstract}

\section{Introduction}

In recent decades, Indigenous populations ${ }^{1}$ across the Western world have become increasingly urbanized. In Canada, the urban Aboriginal population has experienced steady growth since the 1950s, when less than seven percent was urban (Kalbach 1987). Currently, over half of the Aboriginal population is living in cities. According to Statistics

1 The term 'Indigenous' is recognized by the United Nations and by a growing number of scholars to refer to the First Peoples of a region. It usually refers to First Peoples internationally (NAHO 2011).

aboriginal policy studies, vol. 5, no. 1, 2015

www.nativestudies.ualberta.ca/research/aboriginal-policy-studies-aps

ISSN: $1923-3299$ 
Canada, approximately fifty percent of urban Aboriginal peoples are First Nations, fortythree percent identify as Metis, and seven percent are of Inuit descent. ${ }^{2}$

In Canada, as well as in other settler nations, the urbanization of Indigenous peoples has been associated with high levels of geographic mobility between rural areas and cities, as well as within cities (Norris and Clatworthy 2003; Snipp 2004; Taylor and Bell 2004). As mobility flows have increased in recent decades, urban policy and service delivery have struggled to meet the needs of Aboriginal urban newcomers and intra-city movers. Although urban Aboriginal service providers often serve as a key point of entry for newcomers, there remains a distinct need for transitional service support, and adequate and appropriate service provision remains a point of concern (Distasio and Sylvestre 2004; Distasio, Sylvestre, and Wall-Wieler 2013). Although urbanization is by no means a recent phenomenon, adequate transitional supports, including housing, remain a key issue for recent Aboriginal migrants and movers. Housing is of particular significance, as housing distress may drive higher rates of mobility (Belanger, Awosoga, and Weasal Head 2013), and yet the federal government has for decades neglected the housing needs of the Aboriginal population seeking to establish itself in the city, and has focused rather on reserve-based housing (Belanger, Weasal Head, and Awosoga 2012). Internationally, it has been argued that urban service providers have difficulties meeting the transitional needs of mobile Indigenous populations, largely due to complications in providing continuous and adequate care to non-stationary populations (Clatworthy and Norris 2007; CMHC 2002; Prout and Yap 2010; Taylor 1998). According to the United Nations (2010), Indigenous peoples' urban mobility remains an ongoing priority area, as frequent Indigenous movers often experience limited access to health, housing, employment, and education services, broadly due to a lack of adequate access to information, and to resistance on the part of dominant governance structures to acknowledging and valuing Indigenous peoples' right to self-determination and ways of knowing, including participation in, and co-creation of, urban planning and the management of services.

Despite these concerns around mobility and service delivery, little is known regarding the relationships between mobility and service planning, delivery, and use. Aside from the work of Skelton (2002), which highlighted the need for social policy that respects and supports the housing needs and perspectives of mobile, single Aboriginal mothers living in Winnipeg, who were often forced to relocate due to deplorable living conditions and experiences of racism, and that of DeVerteuil and Wilson (2010), who found that urban services do not necessarily meet the cultural and social needs of urban (and mobile) Indigenous populations, there remains a key gap in knowledge.

2 It should be noted that the categories First Nations, Metis, and Inuit fail to acknowledge the multiple tribes, identities, and experiences of Aboriginal peoples in Canada, and also run the risk of homogenizing diverse populations. However, for the sake of this discussion, we use these categories, as well as the collective term Aboriginal, as these are widely agreed upon at this time. This is done with the understanding that state policies have been used to manage these so-called categories of Indigeneity at the geographic and population levels. These racialized categories have been used to displace Aboriginal populations politically and culturally (see Andersen 2008). 
Furthermore, structural inequities and inconsistencies perpetuate a discourse in which mobile Indigenous peoples are often particularly vulnerable, as they are not sufficiently supported by existing social policies. Aboriginal mobility is often construed as a negative practice (Cooke and McWhirter 2011), and it has been suggested that frequent movement may disrupt or have a negative impact on service delivery (Clatworthy and Norris 2007; Prout 2009; Taylor 1998). While research has examined how service provision and government funding affect the identity of First Nations women living in urban areas (Peters 2006), and has documented Indigenous mobility patterns and flows over the past half-century (Norris and Clatworthy 2011), little to no work has examined the relationship between service delivery and mobility. Research also has yet to consider the effect that government policy, or lack thereof, has on planning of and access to services for mobile urban Aboriginal populations. In light of the disconnect among levels of government, funders, and urban Aboriginal communities, this article seeks to examine and address the challenges and limitations of service delivery for mobile urban Aboriginal populations, rather than the challenges that mobility presents to service delivery. The purpose of this paper is therefore to examine the use of and challenges related to accessing urban services, including health, education, employment, housing, and social supports, by mobile urban Aboriginal peoples. More specifically, we focus on how governance structures shape service delivery for mobile Aboriginal peoples in urban Canada, and examine what is needed to support the successful transition of urban Aboriginal movers to and within urban areas.

\section{Situating Indigenous Peoples’ Mobility}

For the purposes of this paper, mobility is considered to refer both to migration, which includes moves between urban and rural/reserve areas, and to residential or intra-city mobility, which refers to a change of residence within a given city (Bell and Brown 2005; Clatworthy and Norris 2007). Migration from reserve to urban areas is largely motivated by a lack of favourable circumstances and opportunities on reserves. Issues include a lack of access to health and social services, education and training; family formation or dissolution; substandard housing; poor environmental conditions; and/or lack of economic and political resources on many reserves (CMHC 1996; Cooke and Belanger 2006; Peters and Robillard 2009). It has been suggested that residential mobility, on the other hand, is largely motivated by experiences with racism in the rental market coupled with substandard housing conditions, poverty, eviction, family violence, and/or crime and safety issues (Clatworthy and Norris 2007; CMHC 2002; McCaskill, FitzMaurice, and Cidro 2011).

Indigenous mobility experiences are similar in Canada, the United States, New Zealand, and Australia, where colonial governments have historically and actively dispossessed Indigenous peoples from their lands and cultural identity through paternalistic and assimilationist policies that have had long-lasting repercussions, and have influenced mobility patterns. In Canada in particular, First Nations peoples had their lands appropriated, their cultural practices outlawed, and their children forcibly removed from their families and homes to attend church- and state-run residential schools, where many young people 
faced brutal abuse (Lavallee and Poole 2009). This agenda to dispossess First Nations people of their lands was realized largely through the reserve system. Although lacking any actual basis in law, Indian Affairs, a federal government department, designed a pass system in the late $19^{\text {th }}$ century meant to confine First Nations peoples to their reserves. Those who left their reserves without a pass were taken into police custody. This segregation restricted mobility into urban areas, and although illegal, remained in practice until the 1930s (Barron 1988). The creation of government-controlled reserve lands, which breached treaties and started a system of segregation that would become a template for South African apartheid, resulted in forced relocation, mobility restrictions, and displacement from traditional lands, as well as removal of Indigenous people from cities (Canada 2014c; Smylie 2009).

Similarly, Metis people who, by the $19^{\text {th }}$ century, were a culturally and politically distinct people, were stripped of their land by government policy that disregarded Metis land rights and privileged settler immigration (Laliberte 2014). While some Metis people have lived in urban areas for generations, and not all Metis people associate with a particular land base, ongoing colonization drove many from their lands and communities to live as a marginalized and hidden people. By the 1950s, a lack of resources as well as overcrowding in First Nations reserve communities, coupled with the lifting of mobility restrictions and a decline in once-vibrant rural Metis communities, contributed to urban migration rates (Andersen and Denis 2003).

This complex history of social, economic, political, and geographic inequality continues to play a role in shaping Aboriginal peoples' mobility. It is also important to recognize that mobile Aboriginal people are unique in that they are not only urban newcomers, moving from one defined geographic area to another, but are also moving within their own traditional territories. Consequently, the mobility picture, by and large, differs between Aboriginal and non-Aboriginal populations, due not only to the frequency with which mobility tends to occur, but also to the distinct context in which Aboriginal mobility is situated. Although distinct, urban Aboriginal movers' histories and status are often not recognized (Peters 2005), and, as a result, urban migrants do not receive special status upon migrating to the city. This is due in part to a lack of eligibility for federal programs and services, which focus on reserve-based populations, as well as reluctance on the part of provincial governments to develop Aboriginal-specific urban policies. It could be argued that federal government policy has encouraged urbanization by underfunding reserve services and declining to recognize Indigenous status within cities.

This complexity around policy and programming is exacerbated by colonial perceptions that have suggested that being urban and Indigenous are somehow incompatible. Early urban migration was perceived by settlers to be problematic, and as a result, government interventions were often "complex and contradictory" as policies did not challenge colonial interpretations of First Nations peoples and culture. For example, urbanization was framed as a cultural change, and it was assumed that urban migrants were rejecting their culture and communities of origin to integrate with mainstream society. Federal programs did, however, provide assistance to early migrants, and facilitated urban employment 
and residence as a way to integrate movers. In later years, urban migration was further supported as First Nations groups began to request support for their own service-delivery initiatives (Peters 2002). By 1972, the federal government recognized the growing need for Friendship Centres, which represent a national infrastructure of service providers and advocates for all urban Aboriginal people. In turn, government implemented the Migrating Native Peoples Program, which would later become the Aboriginal Friendship Centre Program, to provide core funding for Friendship Centre programming and service delivery (National Association of Friendship Centres 2011). Many urban Aboriginal institutions that exist today grew from the Friendship Centre movement (Newhouse 2003). More recently, the Urban Aboriginal Strategy (UAS) has come to address key priority areas for urban Aboriginal peoples, including family, health, job and skill training, and support of youth initiatives. Since 1998, UAS programs have been funded in thirteen cities across Canada. This being said, past and present urban policy does not consider Indigenous rights to self-determination and self-government, and may not represent the needs and interests of all urban Aboriginal communities (Tomiak 2013) or movers.

\section{The Role of Government, and Resulting Gaps in Urban Aboriginal Policy}

Despite the existence of federal programs and funding to facilitate urbanization, there remains a lack of clarity over which level of government has jurisdiction over urban Aboriginal people, and governments continue to avoid clarifying this issue (Peters 2011). As Peters notes, this continues to contribute to the assumption that Aboriginal culture and rights are associated with non-urban areas. Although mobility may at times challenge service provision (Clatworthy and Norris 2007), adequate service programming and delivery are also hampered by factors beyond mobility-specifically, by a policy environment that is still rooted in colonial structures that, despite the growth of successful urban self-governing Aboriginal community organizations and networks, treats Aboriginal peoples as outsiders in cities (Peters 2005). In this way, government programming is not sustainable, as it disregards the call for Aboriginal self-determination and seldom recognizes Aboriginal peoples as co-creators at the policy table (Belanger, Awosoga, and Weasal Head 2013; Walker 2005). Federal, provincial, and municipal governments rarely agree upon financial responsibility for care, resulting in a "policy patchwork" rife with jurisdictional ambiguities and a lack of Aboriginal-specific policy (Lavoie et al. 2011). Consequently, the federal government tends to favour reserve-based funding, and there remains a resistance within the service delivery structure itself to providing culturally appropriate care that privileges Indigenous well-being (DeVerteuil and Wilson 2010). As Lavoie et al. (2011) explain in their analysis of Aboriginal health legislation in Canada, coordinating the needs of Aboriginal communities with the relationships and policies of governments remains an ongoing challenge. 
According to the Canadian Constitution Act of 1867, the federal government is responsible for funding health services and other programs to status Indians ${ }^{3}$ living on reserve. This means that status Indians have the right to live on-reserve and have access to First Nation-administered, federally controlled health services, social housing, and assistance. Although there is nothing in place to prevent the federal government from taking responsibility for urban Aboriginal people, it has largely interpreted its role as being accountable for First Nations people on-reserve, and as a result those who migrate from their reserves to urban or rural areas lose most of the services and benefits to which they have access on reserves. The only program to extend benefits off-reserve is the Non-Insured Health Benefits program, which provides status Indians with eyeglasses, prescription drugs, and medical transportation (Lavoie et al. 2008). This paternalistic policy geographically discriminates against urban status Indians, as they lose most of their status rights upon leaving the reserve boundary (Senese and Wilson 2013). This legislation also completely negates benefits for Metis and non-status Indians who, whether urban or non-urban, are not eligible for these benefits, as the federal government does not recognize constitutional responsibility for these populations.

With the federal government's "ambivalence" toward urban Aboriginal peoples (Abele and Graham 2011), urban issues have appeared sporadically on the federal agenda (RCAP 1996). For more than half a century, federal and provincial governments have disputed who is responsible for supporting the service needs of urban Aboriginal peoples (Peters 2006). Aboriginal service delivery is often downloaded to provincial and local governments as well as to private stakeholders, and provincial bodies or tripartite agreements usually end up funding Aboriginal services at the urban level. This is further complicated by the fact that provinces are constitutionally responsible for delivering health and social services to all citizens of a province, including Metis, non-status Indians, and off-reserve status Indians who are living outside their traditional territories. Furthermore, funding for urban Aboriginal services has not matched the growth of the urban Aboriginal population, and urban Aboriginal services, for the most part, remain grossly underfunded. As a result, the service needs of mobile, urban Aboriginal peoples are often underrepresented, and the urban programming and policy gap remains an issue.

Despite these caveats, some successful multi-level, tripartite government partnerships have emerged to support urban Aboriginal programming (Abele and Graham 2011). One such example is the Urban Aboriginal Strategy (UAS) mentioned in the previous section, in which the federal government has partnered with other levels of government, community organizations, and Aboriginal community members in an effort to increase coordination across jurisdictional scales of governance and to meet community-based needs. In

3 A status Indian is someone registered under the terms and conditions of the Indian Act. Although First Nations is the preferred term used by the Indigenous peoples of Canada, they have historically and legislatively been referred to as Indians. Non-status Indians are not registered under the Indian Act, and relatively few live on reserves. 
Winnipeg specifically, Nguyen (2014) found that one of the key factors to the success of the UAS was that government representatives were invested in it as community members, and that they listened respectfully to the opinions of the committee. While tripartite funding and programming partnerships such as the UAS are increasingly becoming the preferred mechanism to address urban Aboriginal policy gaps and jurisdictional conflicts, these agreements do not necessarily clarify federal, provincial, and municipal service responsibilities for off-reserve, non-status, and Metis peoples, nor do they support Indigenous self-determination. Nevertheless, cross-jurisdictional mechanisms do currently promote more appropriate, coordinated policy responses for urban Aboriginal populations, as various Aboriginal and non-Aboriginal stakeholders come to work together (Lavoie et al. 2008; Abele and Graham 2011).

Increased partnerships can present opportunities for Indigenous self-determination; however, the "collaborative paradigm" does not necessarily result in actual decision-making power, autonomy, or governance for urban Indigenous community organizations (Tomiak 2013). Certainly, under neoliberalism, all service providers have been subject to federal downscaling and privatization of services. Services that were once sheltered under federal and provincial umbrellas are now the responsibility of the nonprofit sector, resulting in an assemblage of organizations that are often left in a liminal space between state and society, as they simultaneously negotiate their autonomy and their financial dependency (Trudeau 2008). While neoliberalism has allowed more local players to contribute to program design and delivery, this often creates contradictory relationships between nonprofit organizations and government, as organizations are faced with the opportunity to increase their capacity by responding to their local community's needs and circumstances, but are simultaneously challenged by government funding restrictions that dictate the activities of nonprofit organizations (Morison 2000; Trudeau 2008).

This being the case, Aboriginal-led service organizations without coordinated urban policy agreements in place tend to receive less ongoing funding than do mainstream service providers (Hanselmann 2001), and the sustainable operation and program delivery of many urban Aboriginal-led organizations ends up being limited to a string of short-term, project-based funding arrangements (Sookraj et al. 2010). As a result, human resource hours must be allocated to securing piecemeal program funding, making it difficult for Aboriginal organizations to deliver sustainable services adequately. Funding instability, a lack of core funding, and the need to compete for a finite pool of resources can lead to inter-agency competition, and often creates scarcity conflicts within the Aboriginal service landscape (Peters 2011). Furthermore, this leaves Aboriginal service representatives with rarely enough time or opportunity to pursue involvement at the policy table (Walker et al. 2011). The following section uses in-depth interviews with Aboriginal service providers and mobile urban Aboriginal peoples to illustrate more clearly the role that jurisdiction plays in shaping urban service delivery and resources for mobile Aboriginal populations. 


\section{Study Site: Winnipeg, Manitoba, Canada}

In order to examine how governance structures shape service delivery for mobile Aboriginal peoples in urban Canada, and to illustrate more clearly what is needed to support the successful transition of urban Aboriginal newcomers who are moving between reserve/ rural and urban areas as well as within cities, thirty-nine qualitative interviews were conducted with Aboriginal urban newcomers, intra-city movers, and Aboriginal-led service providers in the city of Winnipeg, Manitoba, Canada. Winnipeg is an important study site as it is home to the largest urban Aboriginal population in Canada. In 2006, over 68,000 urban dwellers in Winnipeg were Aboriginal, representing just over ten percent of the city's population. Approximately forty percent of the Aboriginal population in Winnipeg is of First Nations descent and approximately sixty percent is Metis. A small percentage (less than one percent) is Inuit (Canada 2012).

Aboriginal peoples' mobility rates are relatively high in Winnipeg. According to the authors' calculations, based on 2006 Census data, twenty-six percent of the Aboriginal population had moved over a one-year period, and fifty-eight percent over a five-year period (Canada 2014a). In contrast, thirteen and thirty-nine percent of the non-Aboriginal population were respectively mobile (Canada 2014b). This represents the highest percentage of intra-city movers among the five Canadian cities with the largest Aboriginal populations. Furthermore, Winnipeg's Aboriginal population is twice as likely to move within the city compared to the non-Aboriginal population.

It should be noted that while this research focuses on experiences of frequent and potentially involuntary mobility, and that interviews were conducted with mobile service users, certainly not all Aboriginal people are highly mobile or socioeconomically vulnerable. Indeed, recent research has pointed to the prevalence of an urban Aboriginal middleincome group, despite statistics suggesting that urban Aboriginal peoples are more likely to be in lower income groups than non-Aboriginal people. Urban Aboriginal households with higher incomes are less likely to move than those with lower or middle incomes (Parriag and Chaulk 2013).

Winnipeg is also home to approximately seventy Aboriginal-led, community-based organizations, some which have been in operation for over twenty years (Silver 2009). The City of Winnipeg also has a unique lineage of tripartite government agreements that started in the 1980s, focusing on inner city revitalization and possessing an Aboriginalfocused component. This city has been called a national leader in its efforts to create policy relationships with urban Aboriginal representatives (Walker et al. 2011). While these relationships have been somewhat flawed in that governments have approached Aboriginal stakeholders at the implementation stage of the policy consultation process, rather than as co-producers from inception through to implementation, Winnipeg remains a leader in terms of its innovative and inclusive consultation processes (Walker et al. 2011). 


\section{Methodology}

This project is the result of a collaborative research partnership with a nonprofit, Aboriginalled service organization called Eagle Urban Transition Centre (EUTC). The Assembly of Manitoba Chiefs (AMC) - a reserve-based but urban-situated political organization that represents First Nations across Manitoba-created EUTC in an effort to fill a service gap that would link mobile Aboriginal populations, both newcomers to the city and intra-city movers, to vital health and social services. Although associated with reserve communities, EUTC is a "status blind" Aboriginal organization, meaning that they provide holistic, culturally relevant transitional support to anyone who identifies as First Nation, Metis, or Inuit. They also provide client advocacy, and work to improve the overall quality of life for urban Aboriginal peoples. EUTC plays a central role in supporting the transition of urban Aboriginal newcomers and is one of the only organizations of its kind in urban Canada. Their client base has nearly doubled each year since 2009, with over 7,000 walk-in clients passing through their doors in 2012. Although another Canadian city, Edmonton, Alberta, has developed a similar program for assisting with urban transition (the Aboriginal Welcome Service Program), these types of transitional supports for urban Aboriginal newcomers remain few in number in the Canadian context.

Working in partnership with EUTC, the first author conducted two sets of in-depth, semi-structured interviews. In an effort to capture a snapshot of mobility experiences within the urban Aboriginal community, recruitment was broad, and was open to First Nations, Metis, and Inuit people. It is not our intention to homogenize urban mobility experiences, but rather to provide an introductory argument about the need for responsive urban Aboriginal policy that effectively addresses the needs and interests of vulnerable, frequently mobile Aboriginal peoples. We conducted interviews with twenty-four urban Aboriginal movers and fifteen representatives from Aboriginal-led urban service organizations. All interviews ran 20 to 120 minutes in length. Aboriginal service providers were defined as being from "status blind" organizations that had some level of experience working with mobile clients, and were from nonprofit organizations. We sought to interview participants from a range of sectors, including health, housing, education and training, employment, and transitional services in order to gain a broad perspective on urban Aboriginal service delivery. We duly recognize that these sectors may be treated as distinct policy environments in and of themselves, and as such may encounter unique challenges. This being the case, we sought to touch upon an array of services that may assist mobile populations in their transitions. Using a purposive sampling strategy, fifteen Aboriginal service providers were recruited. Service providers were identified in consultation with EUTC and through scanning service directories (see Table 1). Participants were contacted via telephone and/or email to establish initial contact, describe the research goals, and enlist interest. Once interest was established, participants were met at their place of employment, or in a public setting (e.g., coffee shop). Participants were asked about their roles in their organizations, how they felt their organizations addressed the service needs of mobile Aboriginal populations, and about the challenges and successes that they experienced in working with urban Aboriginal newcomers and intra-city movers. 
Table 1: Interview Participants from Aboriginal Service Organizations

\begin{tabular}{ll}
\hline Service Sector & Participants \\
Housing & 1. Policy Analyst \\
& 2. Organization Development Manag \\
Employment & 3. Executive Director, Education and \\
& 4. Employment Counselor \\
Education & 5. Director of Education \\
6. Intake Coordinator \\
7. Manager of Community Relations \\
8. Executive Director \\
9. Treatment Worker \\
Social Services
\end{tabular}

Tribal Council

15. Urban Service Advocate Worker

Interviews were also conducted with mobile urban Aboriginal people. These participants were recruited using snowball sampling, in which service providers served as initial contacts, or liaisons, for referring potential participants. Mobile participants also referred their friends or family to participate. A second strategy consisted of posting recruitment flyers in community and neighbourhood centres, universities, banks, grocery stores, and health clinics (Peters and Robillard 2009). In total, five migrants, five residential movers, and fourteen migrants/residential movers were interviewed. Notably, mobile populations can be difficult to reach, and the matter of setting an appropriate sample size 
in qualitative research remains open to interpretation. In the case of this research, we concluded conducting interviews at the point at which no new data was emerging and similar instances were arising repeatedly (Patton 2002). For the purposes of this research, migrants are individuals who had moved from a rural or reserve area to the city. Residential movers are urban-born Aboriginal participants who were mobile, meaning they had moved more than once within the year before the interview. Migrants/residential movers are migrants who had found themselves in a cycle of intra-city mobility upon migrating to the city, sometimes moving back and forth between the reserve and urban areas. Of the twenty-four participants, nine were male and fifteen were female. Participants ranged from 18 to 54 years of age. Nineteen were First Nation and five were of Metis descent. We captured a broad group of participants from an age perspective, given that this research represents one of the first studies of its kind, and as such is exploratory in nature. It is beyond the scope of this paper to do a life-stage analysis; however, we acknowledge that older and younger movers may have different levels of understanding in terms of service access. That being said, the interviews focused on mobility history, use of Aboriginal and/ or non-Aboriginal services within the city, experiences with service use, and perceptions of the impact of mobility on service accessibility. The interviews were conducted in person in mutually agreed-upon public locations.

With full consent from all participants, the interviews with service providers and mobile Aboriginal participants were audio-recorded. The transcribed interviews were analysed using NVivo, a software program that is designed to assist with organizing and coding unstructured, qualitative data. Coding was done with the intention of drawing key themes from the interview data, which were then shared and discussed with key stakeholders. Dominant themes from the interviews included the need to enhance connections between service providers and movers, between service providers themselves, and between scales of service delivery and jurisdiction (i.e., urban-reserve disconnect, the need for more diverse urban service locations); the need for respectful and safe spaces for mobile persons; struggles with program funding arrangements; and the need for continuity of adequate care for mobile populations. The interview findings are discussed in the following section, and are organized by themes related to the service gaps and the relationships between mobile Aboriginal populations and Aboriginal-led service providers, including the need for transitional supports between reserve/rural and urban areas as well as within urban areas; funding restrictions; and continuity of care for mobile urban Aboriginal populations.

\section{Bridging the Gap? Locating Transitional Supports when Migrating to an Urban Centre}

Most Aboriginal service providers who were interviewed indicated that Aboriginal migrants who move from reserve or rural areas to urban communities have difficulty locating service information and providers, particularly in terms of housing and transitional supports. Some mentioned that this information disconnect is due to a programming gap between reserve and urban areas. Given that service providers are often a first point of contact for urban Aboriginal migrants (Distasio and Sylvestre 2004), this gap can have an impact on 
Aboriginal migrants' access to resources and adequate preparation for a move to the city. Service providers stated that as a consequence, upon arriving in the city, migrants are often not only overwhelmed by the intensity of the urban experience, but may also, for example, find themselves in situations of housing crisis or experience adversity in securing service supports for employment or childcare. Although a number of Aboriginal housing programs exist in Winnipeg, as well as in other cities in Canada, the demand for adequate and affordable housing continues to result in long waiting lists and an often a complex application process. As one service provider explained, Aboriginal migrants in particular encounter multiple hurdles in transitioning to the city, including racism and difficulty locating culturally safe support services:

We have a lot of migrants from First Nations communities migrating back and forth ... I think there's a funding and service gap there ... [When] a lot of First Nations people migrate to the city ... they're often moving to the city unprepared and without the supports that they need ... they're already going to struggle with the transition, and they're going to struggle with trying to find the services, but they're also going to ... struggle with battling stereotypes and racial images that are already made upon them before they even get into the city.

\section{-Aboriginal Youth Project Coordinator}

An Aboriginal housing manager echoed similar sentiments, suggesting that migrants are often overwhelmed and underprepared for the transition from reserve/rural to urban areas, as service information, support, and resources are often unavailable, or difficult to obtain, at their point of departure and point of arrival (the city). This could in part be due to a gap in scales of service provision - that is to say that First Nations migrants are transitioning from federally funded reserve programs to provincially or municipally funded off-reserve programming and services. Although there are a number of Aboriginal nonprofit housing providers, service providers and movers both identified access to safe, affordable, and adequate housing as the most important service need for urban newcomers and frequent residential movers. This service gap can also feed into a cycle of residential mobility:

People will come to the city and they haven't realized how different it is from where they live. And so they move here and then they haven't given thought to where they're gonna live ... but then, when you're living in the city it's 'way different than living in a small community. So they're stressed out because they gotta take the bus-it takes forever to get anywhere, to fill out applications, and they can't get a place and they're staying with people and-so, sometimes I wonder if ... they had supports in the community or places to go in the community that would prepare them. 
Movers also spoke about their difficulty and confusion in accessing urban services and information, particularly that which supported housing transition. One migrant explained that since moving to the city for medical care that was not available on reserve, he had been unable to secure adequate housing and employment support:

It's really hard to get help over here [referring to city]. You have to give like an arm and a leg to get some assistance ... I came here on medical aid, but I'd been wanting to leave the reserve for a long time ... I wanted to go to school, that was my main goal ... the challenge right now is finding a place that's affordable and clean. [The government] just leaves us out in the dust. You have to protest or do something dramatic to get some attention or help.

-First Nations Migrant, Male

While movers indicated that they were generally aware that housing, education, and employment support services existed in Winnipeg, they did not know how best to access services, or in some cases where services were located. In the case of the quotation above, some migrants felt as if they had fallen through the cracks. As one Metis migrant suggested, "the services are there, but it's just a matter of finding them." A First Nations migrant who had relocated from her reserve to Winnipeg for education explained that in order to access services comfortably, she felt that she needed to know people who worked for those organizations:

I'm not really clear what organization does what ... I would say, like, people who first move to the city don't really know a lot of the things [referring to service organizations] ... unless like you know this person who works there.

\section{-First Nation Migrant, Female}

This suggests a need for coordinated outreach to movers, in a space or manner that is welcoming. Another migrant, a young parent attending school, also identified the difficulty that she had obtaining support and service information when she transitioned to the city. She suggested that information availability and visibility were key needs, and suggested that a welcome program might be helpful:

What I would suggest is for new Native families that move to Winnipeg to have, y'know, information, pamphlets, like a little welcome type of gift for these people who move so they have this information. They don't have to go out and find itthey have it and they know, like, oh this is where I can go for this and, y'know, stuff like that. That would've made my move a little bit easier.

\section{-First Nation Migrant, Female}

In response to these service knowledge gaps, movers reported using word-of-mouth networks to assist in bridging the information void. Tenuous connections between reserve/ rural and urban programming also create a gap when attempting to identify and locate 
urban housing or transitional support services prior to, and upon, arrival in the city. This gap could be bridged through fostering and supporting service provider relationships and methods of information delivery between rural/reserve and urban areas. It remains the case, however, that federal funding rarely extends the financial resources necessary to do this. As an Aboriginal transition counselor explained, "There's a huge disconnect between the urban resources and the rural First Nation communities."

We'd have more success transitioning people to the city ... if we were able to get out and build stronger relationships with First Nation communities, but ... we don't have those-we don't have, I guess, that option because of funding restrictions.

\section{-Aboriginal Project Coordinator}

More than half of the service providers who were interviewed indicated the importance of extending services, information, relationships, and advocacy beyond the urban boundary by creating interconnections with reserve/rural jurisdictions. However, the allocation of resources represents a key barrier.

\section{Service Delivery and Access for Mobile Urban Aboriginal Populations}

Nearly every participant alluded to how a lack of core funding impeded their time, resources, and capacity to serve the interests of the mobile urban Aboriginal community and to provide advocacy for those in a vulnerable period of transition. An Aboriginal health provider described the difficulties that nonprofit, Aboriginal-led organizations face in terms of securing funding and retaining staff, suggesting that service providers are often forced to wedge their needs into funder criteria, creating restrictions around where and how services are delivered:

It's not like we can go out there and identify a need, design a program around it, and then find a funder. It doesn't work like that. Because funding comes from government, of one level or another, or through [private] funding agencies, but they all have criteria. So you've gotta see what's out here, and see if you can design a program to fit in there. And hopefully the needs you've identified, you can address with that funding stream ... Every year for non-profits it gets tougher and tougher and tougher ... And it makes it very difficult to retain staff because, y'know, when you can't keep up with [those] that have more money.

\section{-Aboriginal Executive Director}

Some service providers expressed the need for mobile service units, or multiple service units throughout the city. A transition counselor who worked with youth suggested of their program that "there needs to be more of these programs stationed throughout the city ... but there also needs to be more of these programs ... out in communities and out in other urban centres" so that movers who are seeking to create ties with service providers as a way 
to ease their urban transition can do so. This program focuses on training and assisting youth in transition into housing, employment, and training, and in providing a culturally relevant and safe space in which clients may do so. This points to the need for targeted distribution of youth and transition services across geographic spaces, including reserves and rural communities, and within cities. This was also true in terms of general healthcare delivery. As a Metis participant suggested:

It would be great if we were able to have satellite programs in other parts of the city, y'know, because, I mean, we're the only urban Aboriginal Health Centre in the whole city, in fact, probably in the whole province, that isn't on reserve.

\section{-Aboriginal Health Service Provider}

There remains a need for mobile and fluid models of service delivery that privilege mobility experiences. Singular as well as stationary models of service delivery can constrain continuity of care for migrants, as well as for those who may move from one area of the city to another. As one residential mover explained: "There are many times I'd be stuck out in [the suburb to which he had moved] and then I'd be thinking to myself, 'Oh no, I hope I don't get ill', as the bulk of Aboriginal services are located in the inner-city area.

\section{Mobility and Continuity of Urban-Based Care}

Aboriginal-led service providers reported difficulty in meeting the needs of residentially mobile Aboriginal populations, as well as those who move between First Nations reserves and the city, as these service providers often do not have the capacity to maintain continuity of care beyond particular geographic boundaries. A participant from an education and training centre discussed how mobility poses a challenge to continued service access and program completion.

[Mobility] impacts on how they [movers] use the services. One huge issue is keeping in contact with them. Our clients have issues with finding safe and affordable housing so they often move from location to location. As a result, it is difficult to provide ongoing support to action plans developed with our clients, as many do move frequently, resulting in longer timelines to action plan completion due to stopped then restarted plans as clients come, leave, then return.

-Aboriginal Director of Education

Almost half of the movers also discussed how mobility affects their continued access to service care. One residential mover expressed her frustration with attempting to maintain support through the use of drop-in centres when moving from neighbourhood to neighbourhood:

It's basically when you do move, and then when you want to go back, then they [service providers] say, "Well, you moved to this area and you can't use this service because you live in that area now." 
Certainly this may be due to capacity restrictions set in place by the service provider, but it also speaks to a larger need for an increase in this type of support. Many drop-in centres have specific catchment areas; however, nearly half the residential movers interviewed used, or volunteered at, drop-in centres, suggesting that these spaces provide important support for those in transition. The existence of service boundaries, whether due to capacity or funding restrictions, may not adequately support the mobility circumstances of intra-city movers. This loss of support is a point of concern, as those who were frequently mobile within the city all moved due to neighbourhood violence or inadequate housing circumstances. A residential mover, who was forced to move her family due to safety and housing issues, explained how connections to drop-in centres and community are interrupted by forced mobility across neighbourhood boundaries:

Oh, I used to stay out in [my previous neighbourhood] and ... I used to go to [a dropin centre] there. And then when I moved from there to [my new neighbourhood], they told me I can't go to that [drop-in centre] anymore 'cuz it's too far for me ... And I asked them, "Well what's the difference? You guys are like almost the same like distance." And they said, well, I passed that boundary ... so I had to go to a different [drop-in centre] ... I didn't know who to talk to and I was like, "Oh, who do I talk to about this?" Didn't feel really comfortable.

-Métis Residential Mover, Female

Jurisdictional gaps can create challenges in terms of service delivery for residential movers relocating across neighbourhoods within the city, as well as for urban migrants moving between reserve/rural and urban boundaries. From a policy and funding perspective, one solution in terms of facilitating service delivery for the urban Aboriginal community is through an organization such as the Aboriginal Council of Winnipeg (ACW). The $\mathrm{ACW}$ is a federally funded initiative, via the UAS, that brings together local governments, Aboriginal organizations, and the private sector. They are an example of a political and advocacy voice that seeks to develop self-governance and to represent First Nations, Metis, and Inuit people living in Winnipeg. They offer economic development, education and training, health services, support for adequate housing, and youth programming in one central location (see Winnipeg 2015). This tripartite supported initiative does provide a good example in the Canadian context of an attempt to close some of the jurisdictional gaps in terms of urban Aboriginal service delivery and policy. The ACW serves as an urban gathering space that is safe and welcoming for urban Aboriginal people, and that also seeks to empower the community and to remove systemic barriers that urban community members may encounter, particularly those in vulnerable transition to or within the city. Organizations within the ACW that were interviewed did speak to ongoing gaps, reflected by the need to extend services beyond neighbourhood boundaries as well as beyond the city. 


\section{Conclusions: Key Findings and Challenges}

Our study suggests that a disconnect among federal, provincial, and municipal levels of government, as well as between urban Aboriginal stakeholders and community organizations, can affect resource allocation and the structure of urban Aboriginal service delivery. This, in turn, affects urban Aboriginal migrants' and residential movers' access to support services. While initiatives such as the UAS indicate a clear shift in terms of federal policy and tripartite agreements that recognize urban Aboriginal communities and the need for the distribution of resources that support urban Aboriginal organizations, the UAS has been criticized for its lack of strategic direction and long-term vision (Abele and Graham 2011) as well as for its lack of consideration for Indigenous rights to self-determination and self-government. Urban Aboriginal governance, and the resulting service landscape, will require collaboration among a multitude of players. Current governance practices rarely meet or represent the needs and interests of urban Aboriginal communities, and the research findings reveal an aspect of this gap in terms of meeting the needs and interests of mobile Aboriginal populations. As Tomiak (2013) and Maaka and Fleras (2000) have suggested, self-determination should be a platform from which to reimagine urban Indigenous governance and to challenge the legitimacy of state boundaries, while strengthening Indigenous jurisdiction over land, identity, and politics. More specific to the context of this research, we must consider how mainstream policy legitimates only certain types of service delivery (i.e., reserve and urban areas are considered distinct and separate; mobile or satellite service delivery is not supported).

As a way to address the "policy patchwork" in a way that is both appropriate and effective, we must consider the diversity of urban Indigenous communities, and that federal, provincial, municipal governments as well as First Nations, Metis, and Inuit organizations and service providers must come to participate collaboratively and, at the very least, as equal contributors in service and program planning, as well as in community building. This must also be done in consideration that a lack of core funding leaves many Aboriginal service providers stretched for resources, with little time or financial capacity to engage in policy development.

These gaps tend to occur largely across reserve, rural and urban boundaries, resulting in a service and information gap for prospective migrants and urban newcomers that may impede their successful urban transition. At the urban level, stationary models that privilege location or singular nodes of service delivery can affect continuity of care for mobile populations. Given that research has suggested that service providers remain an important first point of contact for migrants (Distasio and Sylvestre 2004), and that half the Aboriginal population in Winnipeg uses and relies at least occasionally on Aboriginal services (Environics Institute 2011), these findings remain a point of concern.

Our findings also reveal that Aboriginal migrants experience difficulty obtaining service information and are often not aware what services are available when they are preparing to migrate to the city, as well as upon arrival. Furthermore, those who are mobile within the city have difficulty maintaining continuity of adequate care beyond neighbourhood 
boundaries. The use of mobile or satellite service programs could serve to transcend neighbourhood and urban boundaries.

Before discussing the implications of these findings further, a few limitations deserve mention. First, most of the movers who were interviewed were connected in some way to a service organization. The research may therefore overlook the perspectives and experiences of mobile persons who are more isolated. As well, we do not wish to suggest that urban Indigenous communities should in any way be defined by service providers, nor that all urban Aboriginal peoples use such services, but rather that these spaces provide important points of connection, network, and support-particularly, in the case of this research, for more vulnerable and mobile community members. This segment of the Aboriginal population may have unique service needs, and represents an important area of future research. Furthermore, while this research includes the voices of Metis and First Nations participants, it did not reach the Inuit community, which represents less than one percent of Winnipeg's population. It is not our intention to conflate these identity groups, but for the sake of this paper we seek to provide a broad view of Aboriginal peoples' mobility. We affirm that urban Indigenous peoples are importantly diverse and multi-national in their composition; however, within the context of this paper, and due to its qualitative and indepth nature, we draw upon a smaller sample of participants as a springboard to address the mobile urban Aboriginal community at large as a means to forward the importance of self-governed policy and programming that represents the broader mobile urban community, particularly those who are vulnerable and in transition. Our current goal is to provide a general understanding of the relationship between Aboriginal peoples' mobility and service delivery, which to date remains largely unexplored. These limitations point to the need for future research that addresses the specific needs and concerns of mobile Metis, First Nations, and Inuit people, and that targets particular types of service delivery.

Despite these limitations, the research demonstrates significantly the disconnect that exists between reserve/rural and urban areas. Furthermore, the research is critical to the policy discussion around mobility and service provision, as it draws attention to the experiences of an often-overlooked and underrepresented population. It also highlights federal, provincial, and municipal funding agreements and how these may play out in the urban environment. It is little wonder that Aboriginal peoples' mobility has been construed as negative or disruptive to service delivery, given that it is situated within a colonial context that has generated a patchwork of mismatched and inadequate scales of resource allocation. Although past research has suggested that mobility has an impact on service delivery, little has been done to uncover how and why this might be. By drawing upon the lived experiences of movers, as well as by speaking to Aboriginal service providers, this article demonstrates the need to enhance relationships between reserve/rural and urban service providers, as well as among all levels of government, in order to facilitate the transition of mobile Aboriginal populations. To address these service gaps in earnest, cohesive, tripartite agreements that holistically address the transitional needs of migrating urban Aboriginal residents will be necessary to foster healthy, sustainable urban communities. Based on 
the findings of this research, key policy and research recommendations should address the need for increased transitional housing, and the development of satellite services that bridge urban neighborhoods as well as urban and reserve or rural boundaries.

\section{Strategies for Moving Forward}

Some service providers suggested the need for satellite programs within the city as well as beyond the urban boundary, as mentioned above. Other concrete examples for moving forward include an initiative taken by our community partner EUTC to offer a series of YouTube videos that provide information and support for potential migrants. Making Aboriginal service directories and information accessible to those considering a move to the city is another helpful avenue. Furthermore, developing and supporting other web resources that address questions that migrants have around urban housing, transportation, and training opportunities would also be a useful step in the right direction.

Aboriginal-led service providers also have the potential to inform urban Aboriginal policy, as they often work closely with mobile Aboriginal populations, and have an intimate knowledge of the disjointed resource allocation between reserve/rural and urban spaces. It is a serious disadvantage that voices from these Aboriginal organizations are rarely involved in policy decisions (Walker et al. 2011), but are rather left securing fragmented resources. In order to strengthen tripartite relationships and Aboriginal-governed programming further, all levels of government will need to form sustainable, co-productive relationships, not only with each other, but with Aboriginal political and service organizations (Walker et al. 2011), and to engage in creating a more coherent urban Aboriginal policy framework, more adequate funding arrangements, and a commitment to urban Indigenous selfgovernment (Tomiak 2013). It is time that all levels of government step forward with a long-term, collaborative vision that seeks to improve and maintain the well-being of all urban residents. 


\section{Bibliography}

Abele, F., and K.A.H. Graham. 2011. "Federal Urban Aboriginal Policy: The Challenge of Viewing the Stars in the Urban Night Sky." In Urban Aboriginal Policy Making in Canadian Municipalities, edited by E. J. Peters, 33-52. Montreal \& Kingston: McGill-Queen's University Press.

Andersen, Chris. 2008. "From Nation to Population: The Racialisation of 'Métis' in the Canadian Census. Nations and Nationalism." Nations and Nationalism 14(2): 34768.

Andersen, Chris, and Claude Denis. 2003. "Urban Natives and the Nation: Before and After the Royal Commission on Aboriginal Peoples." Canadian Review of Sociology \& Anthropology 40(4): 373-90.

Barron, F. Laurie. 1988. “The Indian Pass System in the Canadian West, 1882-1935.” Prairie Forum 13(1): 25-42.

Belanger, Yale D., O. Awosoga, and Gabrielle Weasal Head. 2013. "Homelessness, Urban Aboriginal People, and the Need for a National Enumeration." aboriginal policy studies 2(2): 4-33. http://dx.doi.org/10.5663/aps.v2i2.19006.

Belanger, Yale D., Gabrielle Weasal Head, and O. Awosoga. 2012. "Housing and Aboriginal People in Urban Centres: A Quantitative Evaluation." aboriginal policy studies 2(1): 4-25. http://dx.doi.org/10.5663/aps.v2i1.17705.

Bell, M., and D. Brown. 2005. "Measuring Indigenous Mobility in Australia and New Zealand: Methodological and Conceptual Issues." IAOS Satellite Meeting on Measuring Small and Indigenous Populations. Wellington, New Zealand.

Canada. 2012. "Aboriginal Peoples in Canada in 2006: Inuit, Métis and First Nations, 2006 Census.” http://www12.statcan.ca/census-recensement/2006/as-sa/97-558/pdf/97558-XIE2006001.pdf.

———. 2014a. “2006 Aboriginal Population Profile.” http://tinyurl.com/o2bfogd.

———. 2014b. “2006 Community Profiles.” http://tinyurl.com/p4hdmz6.

Canada, Aboriginal Affairs and Northern Development. 2014c. "Treaty Land Entitlement." http://www.aadnc-aandc.gc.ca/eng/1100100034819/1100100034820. 
Clatworthy, S., and M. J. Norris. 2007. “Aboriginal Mobility and Migration: Trends, Recent Patterns, and Implications: 1971-2001." In Aboriginal Policy Research: Moving Forward, Making a Difference, edited by J. P. White, S. Wingert, D. Beavon, and P. Maxim, IV: 207-33. Toronto: Thompson Educational Publishing.

CMHC. 1996. "Migration and Mobility of Canada's Aboriginal Population." Canadian Mortgage and Housing Corporation: Socio-Economic Series.

- - - 2002. "Effects of Urban Aboriginal Residential Mobility." Canadian Mortgage and Housing Corporation: Socio-Economic Series.

Cooke, Martin, and Daniele Belanger. 2006. "Migration Theories and First Nations Mobility: Towards a Systems Perspective." Canadian Review of Sociology and Anthropology 43(2): 141-64.

Cooke, Martin, and Jennifer McWhirter. 2011. "Public Policy and Aboriginal Peoples in Canada: Taking a Life-Course Perspective.” Canadian Public Policy 37: S15-S31.

DeVerteuil, Geoff, and Kathi Wilson. 2010. "Reconciling Indigenous Need with the Urban Welfare State? Evidence of Culturally-Appropriate Services and Spaces for Aboriginals in Winnipeg, Canada." Geoforum 41(3): 498-507.

Distasio, Jino, and Gina Sylvestre. 2004. "First Nations/Métis/Inuit Mobility Study: Final Report." University of Winnipeg. Institute of Urban Studies. Canada.

Distasio, Jino, Gina Sylvestre, and Elizabeth Wall-Wieler. 2013. "The Migration of Indigenous Peoples in the Canadian Prairie Context: Exploring Policy and Program Implications to Support Urban Movers." Geography Research Forum 33: 38-63.

Environics Institute. 2011. "Urban Aboriginal Peoples Study: Winnipeg Report.” Toronto, Ontario, Canada: The Interprovincial Group.

Hanselmann, Calvin. 2001. "Urban Aboriginal People in Western Canada: Realities and Policies.” Edited by Canada West Foundation. Calgary, Alberta, Canada.

Kalbach, W. E. 1987. "Growth and Distribution of Canada's Ethnic Populations, 18711981.” In Ethnic Canada: Identities and Inequalities, edited by L. Dreidger, 82-110. Toronto: Copp Clark Pitman.

Laliberte, Ronald. 2014. "Being Metis: Exploring the Construction, Retention, and Maintenance of Urban Metis Identity." In Indigenous in the City: Contemporary Identities and Cultural Innovation, edited by Evelyn Peters and Chris Andersen, 110-31. Vancouver, British Columbia, Canada: UBC Press. 
Lavallee, Lynn F., and Jennifer M. Poole. 2009. "Beyond Recovery: Colonization, Health and Healing for Indigenous People in Canada." International Journal of Mental Health and Addiction 8(2) (August 18): 271-81.

Lavoie, J., and E. Forget. 2008. "The Cost of Doing Nothing: Implications for the Manitoba Health Care System.” Pimatisiwin: A Journal of Aboriginal and Indigenous Community Health 6(1): 107-21.

Lavoie, Josee, Laverne Gervais, Jessica Toner, Odile Bergeron, and Ginette Thomas. 2008. "Looking for Aboriginal Health in Legislation and Policies, 1970 to 2008: The Policy Synthesis Project.” Prince George, British Columbia, Canada.

- - . 2011. "The Aboriginal Health Legislation and Policy Framework in Canada." Vol. 35. University of Northern British Columbia.

McCaskill, Don, Kevin FitzMaurice, and Jaime Cidro. 2011. “TARP: Toronto Aboriginal Research Project: Final Report.” Toronto Aboriginal Support Services Council. Toronto.

Morison, John. 2000. "The Government-Voluntary Sector Compacts: Governance, Governmentality, and Civil Society." Journal of Law and Society 27(1): 98-132.

NAHO. 2011. "National Aboriginal Health Organization Terminology Guidelines." National Aboriginal Health Organization. http://www.naho.ca/publications/topics/ terminology/.

National Association of Friendship Centres (NAFC). 2011. "National Association of Friendship Centres (NAFC) Letters Patent." aboriginal policy studies 1(3): 103-15. http://dx.doi.org/10.5663/aps.v1i3.12562.

Newhouse, David. 2003. “The Invisible Infrastructure: Urban Aboriginal Institutions and Organizations." In Not Strangers in These Parts: Urban Aboriginal Peoples, edited by David Newhouse and Evelyn J. Peters, 243-53. Canada: Policy Research Initiative.

Nguyen, Mai. 2014. "Building Relationships or Building Roadblocks? A Look at the Winnipeg Urban Aboriginal Strategy." aboriginal policy studies 3(1-2): 54-87. http:// dx.doi.org/10.5663/aps.v3i1-2.17474.

Norris, M. J., and Stewart Clatworthy. 2003. "Aboriginal Mobility and Migration within Urban Canada: Outcomes, Factors, and Implications." In Not Strangers in These Parts: Urban Aboriginal Peoples, edited by D. Newhouse and Evelyn Peters, 51-78. Government of Canada: Policy Research Initiative. 
Norris, Mary Jane, and Stewart Clatworthy. 2011. "Urbanization and Migration Patterns of Aboriginal Populations in Canada: A Half Century in Review (1951 to 2006)." aboriginal policy studies 1(1): 13-77. http://dx.doi.org/10.5663/aps.v1i1.8970.

Parriag, Amanda, and Paul Chaulk. 2013. "The Urban Aboriginal Middle-Income Group in Canada: A Demographic Profile." aboriginal policy studies 2(2): 34-63. http:// dx.doi.org/10.5663/aps.v2i2.19005.

Patton, Michael. 2002. Qualitative Research and Evaluation Methods. 3rd ed. Thousand Oaks, California: Sage.

Peters, E. J. 2011. “Aboriginal Public Policy in Urban Areas: An Introduction.” In Urban Aboriginal Policy Making in Canadian Municipalities, edited by E. J. Peters, 3-32. Montreal \& Kingston: McGill-Queen's University Press.

Peters, Evelyn. 2002. “'Our City Indians': Negotiating the Meaning of First Nations Urbanization in Canada, 1945-1975.” Historical Geography 30: 75-92.

- - - 2005. "Indigeneity and Marginalisation: Planning for and with Urban Aboriginal Communities in Canada." Progress in Planning 63(4) (May): 327-404.

Peters, Evelyn J. 2006. “'[W]e Do Not Lose Our Treaty Rights Outside The ... Reserve’: Challenging the Scales of Social Service Provision for First Nations Women in Canadian Cities." Geojournal 65: 315-27.

Peters, Evelyn J., and Vince Robillard. 2009. “Everything you want is there': The Place of the Reserve in First Nations' Homeless Mobility." Urban Geography 30(6): 652-80.

Prout, S. 2009. "Security and Belonging: Reconceptualising Aboriginal Spatial Mobilities in Yamatji Country, Western Australia." Mobilities 4(2): 177-202.

Prout, S., and M. Yap. 2010. "Indigenous Temporary Mobilities and Service Delivery in Regional Service Centres: A West Kimberley Case Study." Centre for Aboriginal Economic Policy Research. Australia.

RCAP (Report of the Royal Commission on Aboriginal Peoples). 1996. "Perspectives and Realities: Urban Perspectives.” Vol. 4. Minister of Supply and Services Canada.

Senese, L.C., and K. Wilson. 2013. "Aboriginal Urbanization and Rights in Canada: Examining Implications for Health." Social Science \& Medicine 91: 219-28. 
Silver, J. 2009. "Building Resistance: Aboriginal Organizations in Winnipeg's Inner City." Canadian Dimension 43 (1). https://canadiandimension.com/articles/view/ building-resistance-aboriginal-organizations-in-winnipegs-inner-city.

Skelton, I. 2002. "Residential Mobility of Aboriginal Single Mothers in Winnipeg: An Exploratory Study of Chronic Moving." Journal of Housing and the Built Environment 17: 127-44.

Smylie, Janet. 2009. “The Health of Aboriginal Peoples.” In Social Determinants of Health, edited by Dennis Raphael, 2nd ed., 280-301. Toronto, Canada: Canadian Scholars' Press Inc.

Snipp, C. M. 2004. "American Indians and Geographic Mobility: Some Parameters for Public Policy." In Population Mobility and Indigenous Peoples in Australasia and North Amercia, edited by J. Taylor and M. Bell, 184-200. London: Routledge.

Sookraj, D., P. Hutchinson, M. Evans, and M. A. Murphy. 2010. "Aboriginal Organizational Repsonse to the Need for Culturally Appropriate Services in Three Small Canadian Cities." Journal of Social Work 12(2): 136-57.

Taylor, J. 1998. “Measuring Short-Term Population Mobility among Indigenous Australians : Options and Implications." Australian Geographer 29(1): 125-37.

Taylor, J., and M. Bell. 2004. "Population Mobility and Indigenous Peoples in Australasia and North America." In Population Mobility and Indigenous Peoples in Australasia and North America, 1-10. London: Routledge.

Tomiak, Julie. 2013. "Indigenous Governance in Winnipeg and Ottawa: Making Space for Self-Determination." In Aboriginal Policy Research Series: Exploring the Urban Landscape, edited by J. Whyte and J. Bruhn, Volume 8, 31-54. Toronto: Thompson Educational Publishing Inc.

Trudeau, Dan. 2008. “Towards a Relational View of the Shadow State.” Political Geography 27(6) (August): 669-90.

UN. 2010. "Urban Indigenous Peoples and Migration: Fact Sheet." Edited by Seventh Session United Nations. New York: United Nations.

UN-HABITAT. 2010. "Urban Indigenous Peoples and Migration: A Review of Policies, Programmes and Practices.” United Nations Housing Rights Programme. Nairobi. 
United Way. 2010. “Eagle's Eye View: An Environmental Scan of the Aboriginal Community of Winnipeg." Edited by United Way. Winnipeg: United Way Winnipeg and Aboriginal Relations Council.

Walker, Ryan C. 2005. "Social Cohesion? A Critical Review of the Urban Aboriginal Strategy and its Application to Address Homelessness in Winnipeg." Canadian Journal of Native Studies 25(2): 395-416.

Walker, Ryan, James Moore, and Maeengan Linklater. 2011. "More than Stakeholders, Voices, and Tables: Towards Co-Production of Urban Aboriginal Policy in Manitoba." In Urban Aboriginal Policy Making in Canadian Municipalities, edited by Evelyn J. Peters, 160-201. Montreal \& Kingston, Canda: McGill-Queen's University Press.

Winnipeg, Aboriginal Council of. 2015. "Aboriginal Council of Winnipeg." http://www. abcouncil.org/. 